\title{
Effectiveness of multi-drug regimen chemotherapy treatment in osteosarcoma patients: a network meta-analysis of randomized controlled trials
}

\author{
Xiaojie Wang ${ }^{1 \dagger}$, Hong Zheng ${ }^{1 \dagger}$, Tao Shou $^{1}$, Chunming Tang ${ }^{1}$, Kun Miao ${ }^{1}$ and Ping Wang ${ }^{2^{*}}$
}

\begin{abstract}
Background: Osteosarcoma is the most common malignant bone tumour. Due to the high metastasis rate and drug resistance of this disease, multi-drug regimens are necessary to control tumour cells at various stages of the cell cycle, eliminate local or distant micrometastases, and reduce the emergence of drug-resistant cells. Many adjuvant chemotherapy protocols have shown different efficacies and controversial results. Therefore, we classified the types of drugs used for adjuvant chemotherapy and evaluated the differences between single- and multi-drug chemotherapy regimens using network meta-analysis.
\end{abstract}

Methods: We searched electronic databases, including PubMed (MEDLINE), EmBase, and the Cochrane Library, through November 2016 using the keywords "osteosarcoma", "osteogenic sarcoma", "chemotherapy", and "random*" without language restrictions. The major outcome in the present analysis was progression-free survival (PFS), and the secondary outcome was overall survival (OS). We used a random effect network meta-analysis for mixed multiple treatment comparisons.

Results: We included 23 articles assessing a total of 5742 patients in the present systematic review. The analysis of PFS indicated that the T12 protocol (including adriamycin, bleomycin, cyclophosphamide, dactinomycin, methotrexate, cisplatin) plays a more critical role in osteosarcoma treatment (surface under the cumulative ranking (SUCRA) probability 76. 9\%), with a better effect on prolonging the PFS of patients when combined with ifosfamide (94.1\%) or vincristine (81.9\%). For the analysis of OS, we separated the regimens to two groups, reflecting the disconnection. The T12 protocol plus vincristine (94.7\%) or the removal of cisplatinum (89.4\%) is most likely the best regimen.

Conclusions: We concluded that multi-drug regimens have a better effect on prolonging the PFS and OS of osteosarcoma patients, and the T12 protocol has a better effect on prolonging the PFS of osteosarcoma patients, particularly in combination with ifosfamide or vincristine. The OS analysis showed that the T12 protocol plus vincristine or the T12 protocol with the removal of cisplatinum might be a better regimen for improving the OS of patients. However, well-designed randomized controlled trials of chemotherapeutic protocols are still necessary.

Keywords: Osteosarcoma, Chemotherapy drugs, Progression-free survival, Overall survival, Meta-analysis

\footnotetext{
* Correspondence: wangping8766@sina.com

${ }^{\dagger}$ Equal contributors

${ }^{2}$ Department of Thoracic Surgery, the First People's Hospital of Yunnan

Province, Affiliated Hospital of Kunming University of Science and

Technology, No.157 Jinbi Road, Kunming City 650032, Yunnan Province,

China

Full list of author information is available at the end of the article
} 


\section{Background}

Osteosarcoma is the most common type of primary malignant bone tumour. It exhibits a high metastasis rate and is frequently detected in adolescents at sites of rapid bone growth $[1,2]$. Although osteosarcoma is frequently treated by surgical joint amputation or disconnection, the prognosis remains poor in patients with metastatic osteosarcoma [3]. Therefore, the ultimate treatment of this disease not only depends on primary tumour control but also the removal of small metastases. Thus, adjuvant chemotherapy combined with the surgical removal of the primary tumour is needed to reduce the size of the tumour, clear the metastases, and improve progression-free survival (PFS) and overall survival (OS).

Osteosarcoma is also a relatively drug-resistant tumour, and the treatment effect of single-drug chemotherapy is not ideal [4, 5]. Thus, multi-drug regimens are necessary to control tumour cells at various stages of the cell cycle, eliminate local or distant micrometastases, and reduce the emergence of drug-resistant cells [6]. Several systematic reviews have examined osteosarcoma chemotherapy, but the results are controversial. A previous study suggested that ifosfamide-based chemotherapy could significantly improve the PFS and OS of osteosarcoma patients [7]. However, recent traditional meta-analyses have not determined whether ifosfamide application and chemotherapy have similar histological response rates and 5-year PFS and OS in non-metastatic and primary osteosarcoma patients; thus, ifosfamide is not recommended [8-10]. Additionally, in a systematic review concerning the dose of chemotherapy drugs, highdose drugs did not significantly improve the PFS and OS of patients compared to moderate-dose drugs [11-13]. Thus, additional studies are needed to resolve these controversies.

From the 1970 s to the present, many adjuvant chemotherapy protocols have shown various efficacy differences and controversial results. No definitive evidence exists regarding which treatment is more advantageous for clinical application $[14,15]$. The aim of the present study was to analyse the existing chemotherapy protocol through direct and indirect comparisons to guide clinical application. However, an analysis of each type of chemotherapy protocol is too complex and cumbersome. Therefore, in the present study, we classified the types of drugs used in adjuvant chemotherapy and evaluated the differences between single or multi-drug chemotherapy regimens using a network meta-analysis.

\section{Methods}

This network meta-analysis was performed in accordance with Preferred Reporting Items for Systematic Reviews (PRISMA) statement [16].

\section{Data search strategy and selection criteria}

Two authors independently performed the literature search through November 2016 using electronic databases, including PubMed (MEDLINE), EmBase, and the Cochrane Library, with the keywords "osteosarcoma", "osteogenic sarcoma", "chemotherapy", and "random", without language restriction. The bibliographies of the obtained publications and relevant reviews were also assessed to ensure that no relevant studies were inadvertently omitted. The publications included in the present study met the following criteria: (1) randomized controlled trial (RCT) design; (2) inclusion of osteosarcoma patients; (3) examination of two or more groups using different single- or multi-drug regimens; and (4) inclusion of PFS or OS as an outcome. The exclusion criteria consisted of the following: (1) nonRCT studies; (2) studies including patients with other types of sarcomas, such as Ewing sarcoma; (3) nonchemotherapy controlled studies, such as surgery or radiotherapy controlled studies; (4) studies comparing the same chemotherapeutic drug type, such as a drug dose-related study; and (5) non-desired outcome studies. Additionally, reviews, comments, case reports, basic studies, and conference reports were also excluded.

\section{Data extraction}

Two authors independently extracted the following information from eligible studies: first author's name, publication year, location, research time, study register or abbreviation, sample size, average age, ratio of males, type of disease, experimental intervention, control, and follow-up. In the present analysis, the major outcome was PFS, and the secondary outcome was OS, as some patients changed the initial randomized treatment after disease progression. We assessed the methodological quality of the included trials using the Cochrane Collaboration's tool, which assigns grades of "high risk", "unclear risk", or "unclear risk" of bias across the seven specified domains [17].

\section{Statistics analysis}

We initially conducted a pairwise meta-analysis using a random effect model, as this model is likely the most appropriate and conservative methodology accounting for between-trial heterogeneity within each comparison [18]. For dichotomous outcomes, odds ratios (ORs) or logarithm transformation with $95 \%$ confidence intervals (CIs) were calculated to determine the sizes of the effects. We also used a random effect network meta-analysis for mixed multiple treatment comparisons because this analysis fully preserves the within-trial randomized treatment comparisons in each trial [19]. To rank the treatments for each outcome, we used the surface under the cumulative ranking (SUCRA) probabilities [20]. Comparison-adjusted funnel plots were used to determine whether small-study effects 
Table 1 Characteristics of subjects in eligible studies

\begin{tabular}{|c|c|c|c|c|c|c|c|c|c|}
\hline Author & Year & Location & $\begin{array}{l}\text { Research } \\
\text { time }\end{array}$ & $\begin{array}{l}\text { Study register/ } \\
\text { abbreviation }\end{array}$ & $\begin{array}{l}\text { Sample } \\
\text { size }\end{array}$ & $\begin{array}{l}\text { Average } \\
\text { age }^{\mathrm{a}}\end{array}$ & $\begin{array}{l}\text { Male/ } \\
\text { Female }\end{array}$ & $\begin{array}{l}\text { Type of } \\
\text { disease }\end{array}$ & Follow-up \\
\hline Yan Zhang [22] & 2013 & China & $2007-2008$ & NA & 76 & $24.4 \pm 1.7$ & $44 / 32$ & Enneking $\|-\mid\|$ & 5 years \\
\hline Neyssa M. Marina [23] & 2016 & International & 2005-2011 & EURAMOS-1 & $\begin{array}{l}2260 \\
(618)\end{array}$ & $4-40$ & $\begin{array}{l}365 / \\
253\end{array}$ & High grade & $\begin{array}{l}62-63 \\
\text { months }\end{array}$ \\
\hline $\begin{array}{l}\text { Sophie Piperno-Neumann } \\
\text { [24] }\end{array}$ & 2016 & France & $2007-2014$ & OS2006 & 318 & $\begin{array}{l}15.4 \\
(5.8-50.9)\end{array}$ & $\begin{array}{l}179 / \\
136\end{array}$ & High grade & 3.9 years \\
\hline Stefan S. Bielack [25] & 2015 & International & $2005-2011$ & EURAMOS-1 & $\begin{array}{l}2260 \\
(1041)\end{array}$ & $\begin{array}{l}14 \\
(11-16)\end{array}$ & $\begin{array}{l}421 / \\
295\end{array}$ & High grade & 44 months \\
\hline Alessandra Longhi [26] & 2014 & Italy & $2007-2011$ & $\begin{array}{l}\text { EudraCT: } \\
\text { 2006-002676-18 }\end{array}$ & 20 & $\begin{array}{l}34 \\
(11-65)\end{array}$ & $11 / / 9$ & Postrelapse & 73 months \\
\hline \multirow[t]{2}{*}{ J.S. Whelan [27] } & 2012 & Europe & 1982-2002 & $\begin{array}{l}\text { EOI } \\
(\mathrm{BO} 02 / 80831)\end{array}$ & 179 & $3-40$ & $102 / 77$ & High grade & 9.4 years \\
\hline & & & & $\begin{array}{l}\text { EOI } \\
(\mathrm{BO03/80861)}\end{array}$ & 391 & $3-38$ & $\begin{array}{l}261 / \\
130\end{array}$ & High grade & 9.4 years \\
\hline Hui Zhao [28] & 2010 & China & 2002-2007 & NA & 32 & $\begin{array}{l}18.5 \\
(7-68)\end{array}$ & $16 / 16$ & $\begin{array}{l}\text { Lung } \\
\text { metastasis }\end{array}$ & 60 months \\
\hline Alexander J. Chou [29] & 2009 & USA & $2001-2005$ & $\begin{array}{l}\text { CCG/POG } \\
\text { (INT-0133) }\end{array}$ & 91 & $<30$ & $56 / 35$ & $\begin{array}{l}\text { High-grade } \\
\text { intramedullary } \\
\text { metastasis }\end{array}$ & 89 months \\
\hline Paul A. Meyers [30] & 2008 & USA & $2001-2005$ & $\begin{array}{l}\text { CCG/POG } \\
\text { (INT-0133) }\end{array}$ & 662 & $\begin{array}{l}13 \\
(1-30)\end{array}$ & $\begin{array}{l}361 / \\
301\end{array}$ & $\begin{array}{l}\text { High grade, } \\
\text { Non-metastasis }\end{array}$ & 7.7 years \\
\hline Marie-Cecile Le Deley [31] & 2007 & France & 1994-2001 & $\begin{array}{l}\text { SFOP-OS94 } \\
\text { (NCT00180908) }\end{array}$ & 234 & $\begin{array}{l}13.2 \\
(3.1-19.5)\end{array}$ & $\begin{array}{l}131 / \\
103\end{array}$ & High grade & 77 months \\
\hline Paul A. Meyers [32] & 1998 & USA & 1986-1993 & $\begin{array}{l}\text { MSKCC (T12) } \\
\text { protocol }\end{array}$ & 73 & $\begin{array}{l}15.8 \\
(4.6-36.4)\end{array}$ & $42 / 31$ & High grade & 91.4 months \\
\hline Robert L. Souhami [33] & 1997 & International & 1986-1991 & $\begin{array}{l}\text { EOI (T10) } \\
\text { protocol }\end{array}$ & 407 & NA & $\begin{array}{l}261 / \\
130\end{array}$ & $\begin{array}{l}\text { High grade, } \\
\text { Non-metastasis }\end{array}$ & 5.6 years \\
\hline Michael P. Link [34] & 1993 & International & 1982-1984 & MIOS & 36 & NA & NA & $\begin{array}{l}\text { High grade, } \\
\text { Non-metastasis }\end{array}$ & $4-8$ years \\
\hline John H. Edmonson [35] & 1984 & USA & 1976-1980 & Mayo Clinic & 38 & $\begin{array}{l}17 \\
(9-62)\end{array}$ & $24 / 14$ & Postoperation & $\begin{array}{l}31-74 \\
\text { months }\end{array}$ \\
\hline K. Winkler [36] & 1984 & Germany & 1979-1982 & coss -80 & 116 & $\begin{array}{l}14 \\
(5-24)\end{array}$ & $69 / 47$ & High grade & 30 months \\
\hline F. Eilber [37] & 1987 & USA & $1981-1984$ & NA & 112 & $\begin{array}{l}15 \\
(4-75)\end{array}$ & $44 / 15$ & Non-metastasis & 2 years \\
\hline D.R. Sweetnam [38] & 1986 & UK & 1975-1981 & NA & 194 & $1-40$ & $111 / 83$ & $\begin{array}{l}\text { Lung } \\
\text { metastasis }\end{array}$ & $\begin{array}{l}26-94 \\
\text { months }\end{array}$ \\
\hline K. Winkler [39] & 1988 & Germany & 1982-1984 & coss-82 & 125 & 14 & $73 / 52$ & Osteosarcoma & 6 years \\
\hline Vivien H.C. Bramwell [40] & 1992 & Canada & 1983-1986 & $\mathrm{EOI}$ & 198 & NA & $114 / 84$ & High grade & 5 years \\
\hline John C. Ivins [41] & 1976 & USA & 1974-1975 & Mayo Clinic & 26 & NA & NA & Osteosarcoma & 15 months \\
\hline C. Jasmin [42] & 1978 & France & 1976- & EORTC & 27 & $\begin{array}{l}18 \\
(9-28)\end{array}$ & $13 / 14$ & Osteosarcoma & 2 years \\
\hline Gilchrist GS [43] & 1978 & USA & NA & NA & 32 & NA & NA & Osteosarcoma & 753 days \\
\hline J.M.V. Burgers [44] & 1988 & Netherlands & 1978-1983 & $\begin{array}{l}\text { EORTC-SIOP03 } \\
(20781)\end{array}$ & 140 & $1-30$ & $87 / 53$ & Osteosarcoma & 5 years \\
\hline
\end{tabular}


were present in the analysis conducted in the present study [21]. All tests were two-tailed, and a $p$ value of less than 0.05 was considered statistically significant. Data analyses were performed using STATA software (version 14.0; Stata Corporation, College Station, TX, USA).

\section{Results}

\section{Literature search}

In the present study, 747 articles were identified after the duplicates were removed. A total of 678 articles were excluded after the titles and abstracts were screened. The full texts of the remaining 69 articles were assessed, and the following types of studies were removed: non-randomized design (19); comparisons of the same type of chemotherapeutic drug (12); duplications or secondary studies (9); non-controlled studies (2); no desired outcomes (2); and other sarcoma studies (2). Eventually, 23 articles assessing a total of 5742 patients were included in the present systematic review [22-44] (Fig. 1, Table 1).

The included studies were published from 1976 to 2016 and were researched from 1974 to 2014 . The analysis contained several multicentre large-scale studies, such as The European and American Osteosarcoma Study Group-1 (EURAMOS-1), Osteosarcoma 2006 (OS2006), and the Symposium of the Cooperative Osteosarcoma Study Group (COSS-80). Many studies contained duplicate reports. Thus, we included relatively recently published studies and referred to the outcomes of the duplicate reports. All age groups of patients were included, and slightly more men than women were included. All studies included patients with osteosarcoma defined according to a pathological diagnosis. In addition, four studies included osteosarcoma patients without metastasis, two studies included metastasis patients, and one study included relapse patients. Most studies initiated chemotherapy prior to surgery. The longest median follow-up period was 9.4 years (Table 1). All included studies had an RCT design without blinding, and most randomizations were not rigorous. However, the assessed outcome was objective; thus, the overall quality of the included studies was not ideal but was acceptable (Additional file 1: Figure S1).

For chemotherapeutic drug application, we investigated all types of drugs used in the intervention arms and classified each of the drugs of the experimental arms

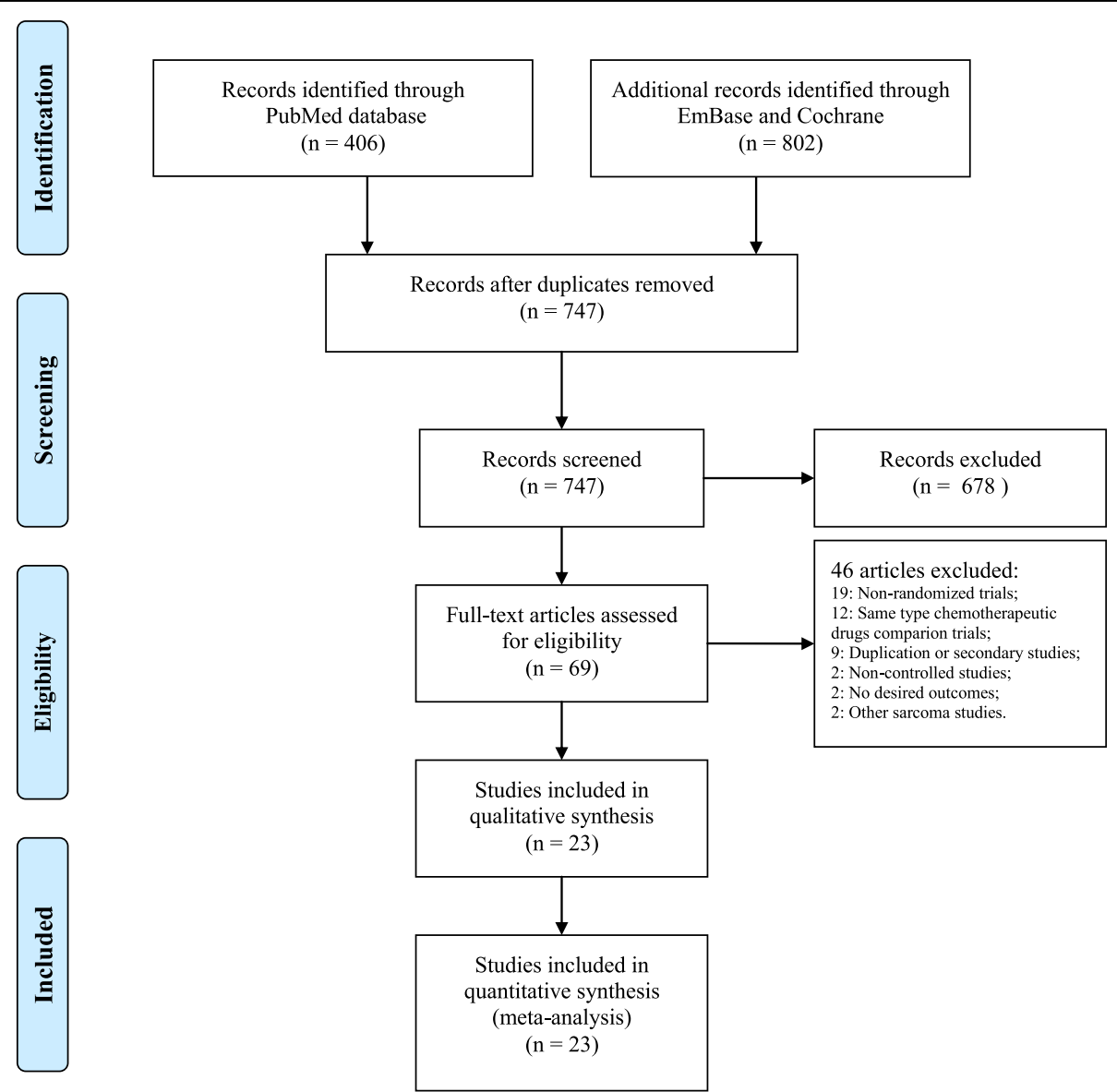

Fig. 1 PRISMA flowchart illustrating the selection of studies included in the present analysis 
by alphabetical order. The present study did not include a comprehensive analysis, reflecting the characteristics of applied chemotherapeutic protocols, as most application stages, durations, and dosages of drugs were different in different protocols (Table 2). Drugs showing no chemotherapeutic effect, such as granulocyte colonystimulating factor (G-CSF) and muramyl tripeptide, were excluded. Drugs that may be included in chemotherapy, such as mistletoe, were included in the present analysis.

For the PFS analysis, we extracted all studies of 5-year PFS or the longest follow-up period for PFS. In the present study, we analysed 16 types of multi-drug regimens. Four multi-drug regimens were directly compared to a blank control, which indicated treatment without chemotherapy. In this analysis, the nodes were weighted according to the number of studies evaluated for each treatment, and the edges were weighted according to the precision of the direct estimate for each pairwise comparison (Fig. 2a). In network pairwise comparisons, the
$\mathrm{ABCDM}$ (all protocol abbreviations are defined in Table 2) regimen was superior to the ACML $(\log \mathrm{OR}$, 1.38; 95\% CI, 0.09-2.68) and Blank (logOR, 1.30; 95\% $\mathrm{CI}, 0.19-2.41)$ regimens for the PFS outcome. The ABCDMP regimen was superior to the ACML $(\log \mathrm{OR}$, 2.14; 95\% CI, 0.45-3.84), AML (logOR, 2.13; 95\% CI, $0.00-4.26)$, Blank (logOR, 2.06; 95\% CI, 0.50-3.62), and ML regimens (logOR, 2.24; 95\% CI, 0.22-4.27), and the ABCDMPI regimen, combining $A B C D M P$ with ifosfamide, was superior to the ABCDMP regimen alone (logOR, 0.84; 95\% CI, 0.09-1.59). The ABCDMPI regimen was also superior to the ACML (logOR, 2.98; 95\% CI, 1.13-4.84), AML (logOR, 2.97; 95\% CI, 0.71-5.23), Blank (logOR, 2.90; 95\% CI, 1.17-4.63), ML (logOR, 3.08; 95\% CI, 0.92-5.24), and N (logOR, 2.75; 95\% CI, $0.22-5.28)$ regimens in the network comparisons. Moreover, the $A B C D M P$ regimen in combination with vincristine (ABCDMPL) was superior to the ACML $(\log \mathrm{OR}$, 1.89; 95\% CI, 0.14-3.64), AMP (logOR, 0.46; 95\% CI,

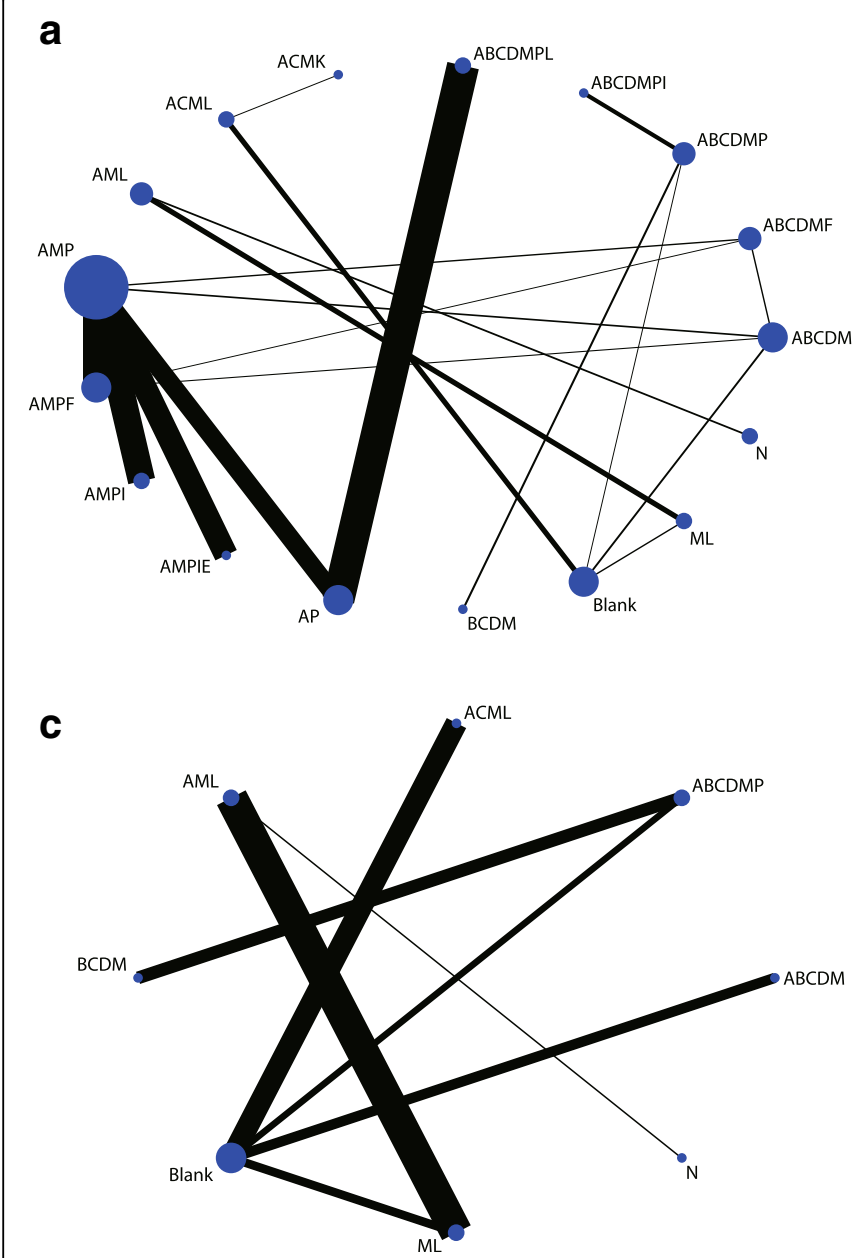

b

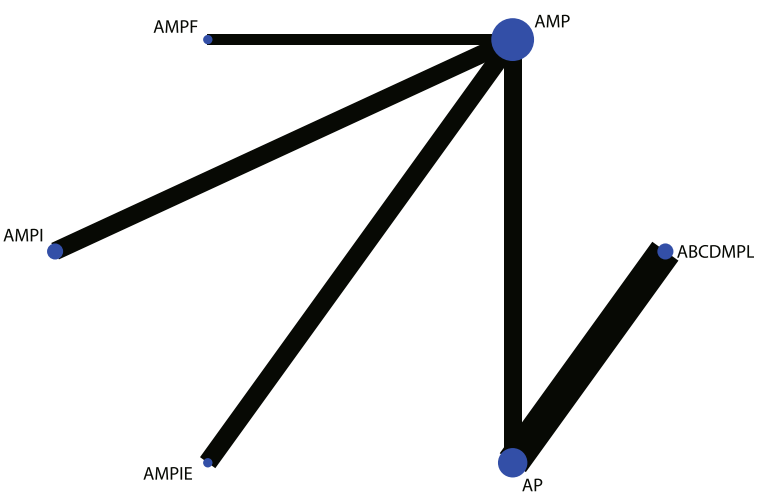

Fig. 2 Network of comparisons for all outcomes included in the analyses. a Progression-free survival. b Overall survival, part one. c Overall survival, part two. Abbreviations: A adriamycin, $B$ bleomycin, $C$ cyclophosphamide, $D$ dactinomycin, $E$ etoposide, $F$ interferon, / ifosfamide, $K$ alkeran, $L$ vincristine, $M$ methotrexate, $N$ transfer factor, $P$ cisplatin 
0.01-0.90), AMPF (logOR, 0.64; 95\% CI, 0.11-1.18), and Blank (logOR, 1.80; 95\% CI, 0.19-3.42) regimens. No other significant differences were found among these regimens (Additional file 2: Table S1). Based on the SUCRA rank, the ABCDMPI regimen was the most likely treatment to improve PFS in osteosarcoma patients (94.1\%), followed by the ABCDMPL (81.9\%) and ABCDMP (76.9\%) regimens. Additionally, the comparisonadjusted funnel plot used to assess publication bias and determine the presence of small-study effects did not suggest any publication bias (Additional file 3: Figure S2a). In addition, some regimens were not included in the network meta-analysis, reflecting a disconnection, and a traditional meta-analysis showed no significant difference between interventions, except for APIZ compared to MIE (OR, 2.27; 95\% CI 1.02-5.04) (Fig. 3).

For the OS analysis, we separated the regimens into two groups, reflecting the disconnection. The first group included AMP, AMPF, AMPI, AMPIE, AP, and ABCDMPL. Four regimens were directly compared to $A M P$, and we directly compared $A P$ and $A B C D M P L$ (Fig. 2b). In the network comparisons, the ABCDMPL regimen showed a significant advantage compared to the AMP $(\log \mathrm{OR}, 0.47 ; 95 \% \mathrm{CI}, 0.02-0.92)$, AMPF $(\log \mathrm{OR}$, 0.65 ; 95\% CI, $0.01-1.29$ ), and AP (logOR, 0.31; 95\% CI, 0.04-0.57) regimens (Additional file 4: Table S2). The results showed that $\mathrm{ABCDMPL}$ was most likely the best regimen for improving the OS (94.7\%) of osteosarcoma patients, followed by the AP (58.3\%) and AMPIE (56.8\%) regimens. The second group included $A B C D M$, ABCDMP, ACML, BCDM, ML, and N. Four regimens were directly compared to the Blank condition (Fig. 2c). In the network comparison, the $\mathrm{ABCDM}$ regimen was superior to the AML (logOR, 1.99; 95\% CI, 0.14-3.84), Blank (logOR, 1.54; 95\% CI, 0.37-2.70), and ML (logOR, 1.76; 95\% CI, 0.03-3.49) regimens, and no other significant difference was found among comparisons (Additional file 5: Table S3). Regarding rank, ABCDM (89.4\%) was most likely to be the best regimen, followed by $\mathrm{N}(70.1 \%)$ and BCDM (60.9\%). The comparisonadjusted funnel plot showed no obvious publication bias (Additional file 3: Figure S2b and c). A comparison of regimens not included in the network meta-analysis revealed that APIR had a significant advantage over API in improving the OS (OR, 3.48; 95\% CI, 1.17-10.32) of the patients (Fig. 3). However, this result was based on a single study and lacked precision and robustness.

\section{Discussion}

In the present study, we analysed single- or multidrug regimens of chemotherapy for the treatment of osteosarcoma using a network meta-analysis. We did

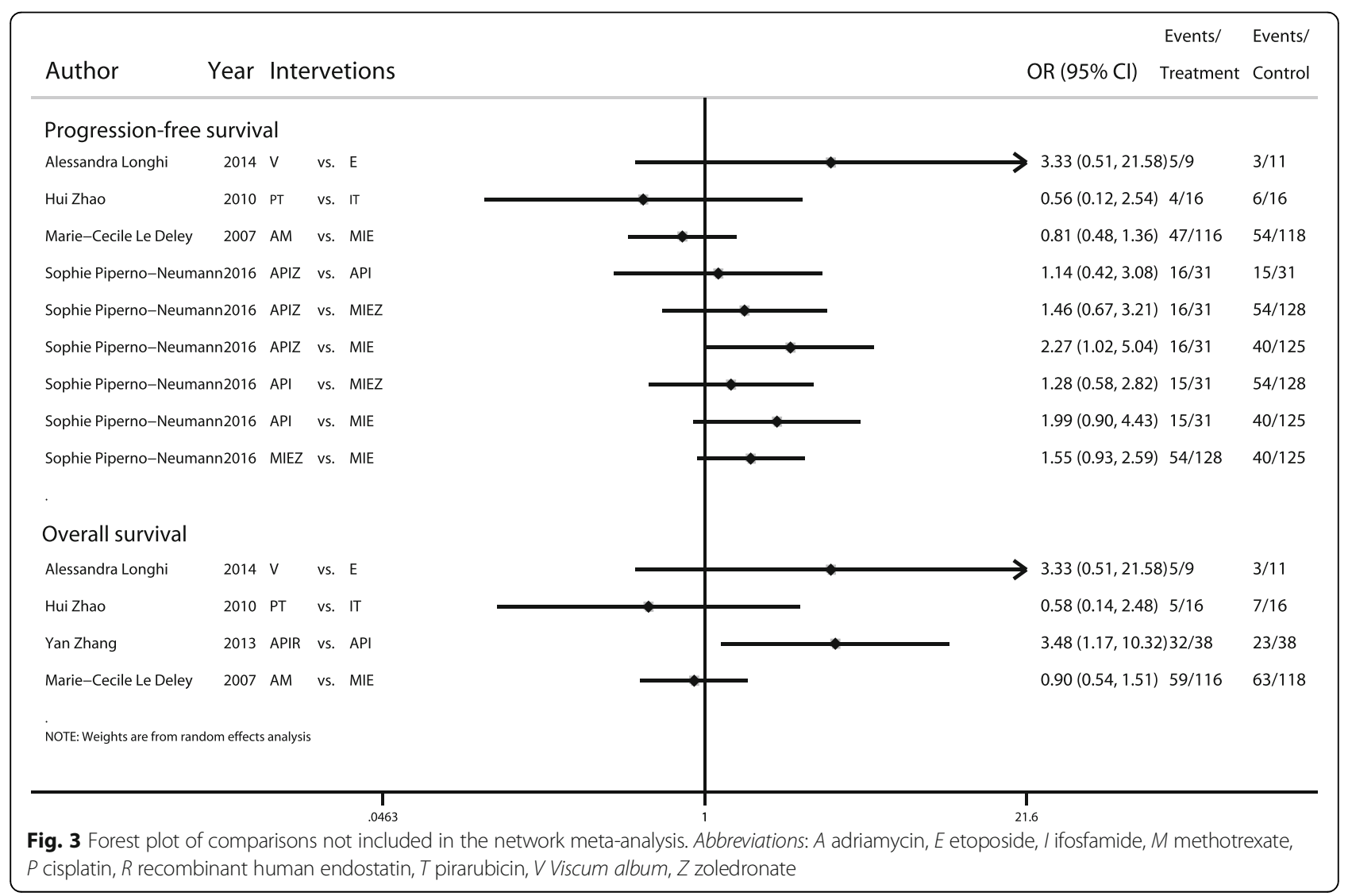


Table 2 Interventions and abbreviations for eligible studies

\begin{tabular}{|c|c|c|c|c|c|c|}
\hline Author & Year & $\begin{array}{l}\text { Study register/short } \\
\text { name }\end{array}$ & Intervention & Abbr. & Control & Abbr. \\
\hline Yan Zhang [22] & 2013 & NA & $\begin{array}{l}\text { Adriamycin; cisplatin; ifosfamide; } \\
\text { recombinant human endostatin }\end{array}$ & APIR & $\begin{array}{l}\text { Adriamycin; cisplatin; } \\
\text { ifosfamide }\end{array}$ & API \\
\hline Neyssa M. Marina [23] & 2016 & EURAMOS-1 & $\begin{array}{l}\text { Adriamycin; methotrexate; } \\
\text { cisplatin }\end{array}$ & AMP & $\begin{array}{l}\text { Adriamycin; methotrexate; } \\
\text { cisplatin; ifosfamide; } \\
\text { etoposide }\end{array}$ & AMPIE \\
\hline \multirow[t]{2}{*}{$\begin{array}{l}\text { Sophie Piperno-Neumann } \\
\text { [24] }\end{array}$} & 2016 & OS2006 & $\begin{array}{l}\text { Methotrexate; ifosfamide; } \\
\text { etoposide; zoledronate }\end{array}$ & MIEZ & $\begin{array}{l}\text { Methotrexate; ifosfamide; } \\
\text { etoposide }\end{array}$ & MIE \\
\hline & & & $\begin{array}{l}\text { Adriamycin; cisplatin; ifosfamide; } \\
\text { zoledronate }\end{array}$ & APIZ & $\begin{array}{l}\text { Adriamycin; cisplatin; } \\
\text { ifosfamide }\end{array}$ & API \\
\hline Stefan S. Bielack [25] & 2015 & EURAMOS-1 & $\begin{array}{l}\text { Adriamycin; methotrexate; } \\
\text { cisplatin; interferona- } 2 \beta\end{array}$ & AMPF & $\begin{array}{l}\text { Adriamycin; methotrexate; } \\
\text { cisplatin }\end{array}$ & AMP \\
\hline Alessandra Longhi [26] & 2014 & $\begin{array}{l}\text { EudraCT: } \\
\text { 2006-002676-18 }\end{array}$ & Viscum album & V & Etoposide & $E$ \\
\hline \multirow[t]{2}{*}{ J.S. Whelan [27] } & 2012 & $\begin{array}{l}\mathrm{EOI} \\
(\mathrm{BO02} / 80831)\end{array}$ & $\begin{array}{l}\text { Adriamycin; methotrexate; } \\
\text { cisplatin }\end{array}$ & AMP & Adriamycin; cisplatin & AP \\
\hline & & $\begin{array}{l}\mathrm{EOI} \\
(\mathrm{BO03/80861)}\end{array}$ & $\begin{array}{l}\text { Adriamycin; bleomycin; } \\
\text { cyclophosphamide; dactinomycin; } \\
\text { methotrexate; cisplatin; vincristine }\end{array}$ & ABCDMPL & Adriamycin; cisplatin & AP \\
\hline Hui Zhao [28] & 2010 & NA & Cisplatin; pirarubicin & PT & Ifosfamide; pirarubicin & IT \\
\hline Alexander J. Chou [29] & 2009 & $\begin{array}{l}\text { CCG/POG } \\
\text { (INT-0133) }\end{array}$ & $\begin{array}{l}\text { Adriamycin; methotrexate; } \\
\text { cisplatin }\end{array}$ & AMP & $\begin{array}{l}\text { Adriamycin; cisplatin; } \\
\text { methotrexate; ifosfamide }\end{array}$ & AMPI \\
\hline Paul A. Meyers [30] & 2008 & $\begin{array}{l}\text { CCG/POG } \\
\text { (INT-0133) }\end{array}$ & $\begin{array}{l}\text { Adriamycin; methotrexate; } \\
\text { cisplatin }\end{array}$ & AMP & $\begin{array}{l}\text { Adriamycin; cisplatin; } \\
\text { methotrexate; ifosfamide }\end{array}$ & AMPI \\
\hline Marie-Cecile Le Deley [31] & 2007 & $\begin{array}{l}\text { SFOP-OS94 } \\
\text { (NCT00180908) }\end{array}$ & Adriamycin; methotrexate & AM & $\begin{array}{l}\text { Methotrexate; ifosfamide; } \\
\text { etoposide }\end{array}$ & MIE \\
\hline Paul A. Meyers [32] & 1998 & $\begin{array}{l}\text { MSKCC (T12) } \\
\text { protocol }\end{array}$ & $\begin{array}{l}\text { Adriamycin; bleomycin; } \\
\text { cyclophosphamide; dactinomycin; } \\
\text { methotrexate; cisplatin }\end{array}$ & ABCDMP & $\begin{array}{l}\text { Bleomycin; } \\
\text { cyclophosphamide; } \\
\text { dactinomycin; } \\
\text { methotrexate; }\end{array}$ & $\mathrm{BCDM}$ \\
\hline Robert L. Souhami [33] & 1997 & $\begin{array}{l}\mathrm{EOI}(\mathrm{T} 10) \\
\text { protocol }\end{array}$ & $\begin{array}{l}\text { Adriamycin; bleomycin; } \\
\text { cyclophosphamide; dactinomycin; } \\
\text { methotrexate; vincristine }\end{array}$ & ABCDMPL & Adriamycin; cisplatin & AP \\
\hline Michael P. Link [34] & 1993 & MIOS & $\begin{array}{l}\text { Adriamycin; bleomycin; } \\
\text { cyclophosphamide; dactinomycin; } \\
\text { methotrexate; cisplatin }\end{array}$ & ABCDMP & Blank & Blank \\
\hline John H. Edmonson [35] & 1984 & Mayo Clinic & Methotrexate; vincristine & $\mathrm{ML}$ & Blank & Blank \\
\hline \multirow[t]{2}{*}{ K. Winkler [36] } & 1984 & coss -80 & $\begin{array}{l}\text { Adriamycin; bleomycin; } \\
\text { cyclophosphamide; dactinomycin; } \\
\text { methotrexate; interferon }\end{array}$ & ABCDMF & $\begin{array}{l}\text { Adriamycin; } \\
\text { methotrexate; cisplatin; } \\
\text { interferon }\end{array}$ & AMPF \\
\hline & & & $\begin{array}{l}\text { Adriamycin; bleomycin; } \\
\text { cyclophosphamide; dactinomycin; } \\
\text { methotrexate; }\end{array}$ & $\mathrm{ABCDM}$ & $\begin{array}{l}\text { Adriamycin; } \\
\text { methotrexate; cisplatin }\end{array}$ & AMP \\
\hline F. Eilber [37] & 1987 & NA & $\begin{array}{l}\text { Adriamycin; bleomycin; } \\
\text { cyclophosphamide; dactinomycin; } \\
\text { methotrexate; }\end{array}$ & $A B C D M$ & Blank & Blank \\
\hline D.R. Sweetnam [38] & 1986 & NA & $\begin{array}{l}\text { Adriamycin; methotrexate; } \\
\text { vincristine }\end{array}$ & $\mathrm{AML}$ & $\begin{array}{l}\text { Methotrexate; } \\
\text { vincristine }\end{array}$ & $\mathrm{ML}$ \\
\hline K. Winkler [39] & 1988 & coss -82 & $\begin{array}{l}\text { Adriamycin; bleomycin; } \\
\text { cyclophosphamide; dactinomycin; } \\
\text { methotrexate; cisplatin; } \\
\text { ifosfamide }\end{array}$ & ABCDMPI & $\begin{array}{l}\text { Adriamycin; bleomycin; } \\
\text { cyclophosphamide; } \\
\text { dactinomycin; } \\
\text { methotrexate; cisplatin; }\end{array}$ & ABCDMP \\
\hline Vivien H.C. Bramwell [40] & 1992 & $\mathrm{EOI}$ & Adriamycin; methotrexate; cisplatin & AMP & Adriamycin; cisplatin & AP \\
\hline John C. Ivins [41] & 1976 & Mayo Clinic & Transfer factor & $\mathrm{N}$ & $\begin{array}{l}\text { Adriamycin; } \\
\text { methotrexate; vincristine }\end{array}$ & AML \\
\hline
\end{tabular}


Table 2 Interventions and abbreviations for eligible studies (Continued)

\begin{tabular}{|c|c|c|c|c|c|c|}
\hline C. Jasmin [42] & 1978 & EORTC & $\begin{array}{l}\text { Adriamycin; cyclophosphamide; } \\
\text { methotrexate; vincristine }\end{array}$ & ACML & $\begin{array}{l}\text { Adriamycin; } \\
\text { methotrexate; } \\
\text { cyclophosphamide; } \\
\text { alkeran }\end{array}$ & ACMK \\
\hline Gilchrist GS [43] & 1978 & NA & $\begin{array}{l}\text { Adriamycin; methotrexate; } \\
\text { vincristine }\end{array}$ & AML & Transfer factor & N \\
\hline J.M.V. Burgers [44] & 1988 & $\begin{array}{l}\text { EORTC-SIOP03 } \\
(20781)\end{array}$ & $\begin{array}{l}\text { Adriamycin; cyclophosphamide; } \\
\text { methotrexate; vincristine }\end{array}$ & $\mathrm{ACML}$ & Blank & Blank \\
\hline
\end{tabular}

Abbreviations: CCG Children's Cancer Group, COSS Cooperative Osteosarcoma Study Group, EOI the European Osteosarcoma Intergroup, EORTC European Organization for Research on Treatment of Cancer, EURAMOS-1 The European and American Osteosarcoma Study Group, MIOS The Multi-institutional Osteosarcoma Study, MSKCC Memorial Sloan Kettering Cancer Center, SFOP Societe Francaise d'Oncologie Pediatrique, SSG the Scandinavian Sarcoma Group, NA not available

not analyse the chemotherapeutic effect according to protocols because the application stage, duration, and dosage of each drug varied. The PFS analysis showed that the $A B C D M P I, A B C D M P L$, and $A B C D M P$ regimens were most likely to improve PFS in osteosarcoma patients. In the present study, the ABCDMP regimen played a critical role in a treatment involving the T12 protocol (including adriamycin, bleomycin, cyclophosphamide, dactinomycin, methotrexate, cisplatin) used at the Memorial Sloan Kettering Cancer Center (MSKCC) between 1986 and 1993. This more intensive preoperative regimen comprised two courses of cisplatinum and doxorubicin in addition to a high dose of methotrexate and bleomycin, cyclophosphamide, and dactinomycin [32]; it showed a better effect on prolonging the PFS of patients when combined with ifosfamide or vincristine. However, these results are partially supported by a previous view that ifosfamide-based chemotherapy significantly improves the PFS of osteosarcoma patients [7]. In the secondary outcome analysis, we also observed that the regimens with more types of drugs showed better results, but use of a transfer factor also showed advantages. However, these results should be considered with caution, as most studies changed the initial protocol and required more active chemotherapy with metastasis or progression. Therefore, the effective gap between interventions could be reduced, resulting in bias. The practice of changing the chemotherapy regimen is common, correct, and ethical in clinical practice.

Despite the present results, it is undeniable that when the number of different types of chemotherapeutic drugs increases, the cytotoxicity and adverse effects will also simultaneously increase. Thus, a balance exists, suggesting that multi-drug regimens could significantly prolong the PFS of osteosarcoma patients but lead to more serious adverse effects. Adverse effects are common in chemotherapy and include nephrotoxicity, ototoxicity, and bone marrow suppression. Serious adverse effects will affect the application of the chemotherapy programme and even the quality of life of patients.
Thus, in clinical practice, cytoprotective agents, such as muramyl tripeptide, are also frequently and simultaneously used for chemotherapy. However, this agent is not widely used, and the literature did not show that cytoprotective agents significantly improved the PFS and OS of patients [29]. Therefore, in the present study, we did not analyse the use of cytoprotective agents. In addition, Viscum album, transfer factor, and recombinant human endostatin are nontraditional chemotherapy drugs that show a cytotoxicity effect. Although they are controversial, we still included these types of drugs in the present analysis.

In the present study, neoadjuvant chemotherapy was used in most included studies. Neoadjuvant chemotherapy includes the administration of chemotherapeutic agents prior to the main treatment, and this regimen has several advantages: (1) It can eliminate micrometastases early to avoid metastases caused by delayed surgery or low resistance. (2) It can control the primary tumour and reduce the chance of surgical tumour spread. (3) It can assess the chemotherapeutic effect and guide the postoperative chemotherapy. (4) It can assess the prognosis earlier. Although the results of RCTs suggested no significant effect on the outcome of patients when comparing preoperative chemotherapy to postoperative chemotherapy [45], neoadjuvant chemotherapy for limb salvage and the surgical process is still worthy of clinical application.

In addition, several studies compared intra-arterial or intravenous chemotherapeutic infusion. When the same regimens were applied, no significant differences were observed in the chemotherapy response between intra-arterial and intravenous infusion [46, 47]. However, some studies suggested that intra-arterial infusion has a more active effect $[48,49]$. Regarding the dosage of chemotherapeutic agents, comparisons of a high or moderate dose of methotrexate have primarily been described. A high dose of methotrexate was more widely used in patients who could tolerate this drug. However, in small-sample RCTs of children with osteosarcoma, a significant difference in outcome was not observed between different dosages [50-52].

We systematically analysed chemotherapeutic regimens for osteosarcoma patients using a network 
meta-analysis, although individual chemotherapeutic protocols could not be analysed. In the present study, multi-drug regimens, such as the T12 protocol plus ifosfamide or vincristine, had a better effect on prolonging the PFS and OS of osteosarcoma patients. Further research with well-designed, double-blinded RCTs is still necessary, as the psychological evidence might also influence patient outcomes. In addition, further trials using relatively well-developed chemotherapeutic protocols would be beneficial to analyse the differences among multiple chemotherapeutic protocols.

\section{Limitations}

There are several limitations to the present study. First, the present analysis was performed at a study level, not at an individual level. Second, for chemotherapy, cytoprotective agents might also improve the survival time of patients by reducing the chemotherapy-induced damage to normal tissue, but these drugs were not analysed in this study. Third, we did not perform the Grading of Recommendations Assessment, Development and Evaluation in the present analysis, as all included studies had an RCT design without blind concealment, and most of the results showed a low risk of imprecision.

\section{Conclusions}

In conclusion, the T12 protocol has a better effect on prolonging the PFS of osteosarcoma patients when combined with ifosfamide or vincristine. For the OS, the T12 protocol plus vincristine or the removal of cisplatinum also represents the best regimen. Further RCTs of chemotherapeutic protocols are still necessary.

\section{Additional files}

Additional file 1: Figure S1. Risk of bias graph of each included study. (EPS $2203 \mathrm{~kb}$ )

Additional file 2: Table S1. The league table of the network for the progression-free survival estimates the treatments according to their relative effects. (DOCX $19 \mathrm{~kb}$ )

Additional file 3: Figure S2. Comparison-adjusted funnel plots for assessing all outcomes. a. Progression-free survival; b. Overall survival, part one; c. Overall survival, part two. (EPS $888 \mathrm{~kb}$ )

Additional file 4: Table S2. The league table of the network for the overall survival estimates the treatments according to their relative effects for first part. (DOCX $14 \mathrm{~kb}$ )

Additional file 5: Table S3. The league table of the network for the overall survival estimates the treatments according to their relative effects for second part. (DOCX $14 \mathrm{~kb}$ )

\section{Abbreviations}

A: Adriamycin; B: Bleomycin; C: Cyclophosphamide; CCG: Children's Cancer Group; COSS: Cooperative Osteosarcoma Study Group; CTs: Confidence intervals; D: Dactinomycin; E: Etoposide; EOI: The European Osteosarcoma Intergroup; EORTC: European Organization for Research on Treatment of Cancer; EURAMOS-1: The European and American Osteosarcoma Study Group;
F: Interferon; G-CSF: Granulocyte colony stimulating factor; I: Ifosfamide; K: Alkeran; L: Vincristine; M: Methotrexate; MIOS: The Multi-institutional Osteosarcoma Study; MSKCC: Memorial Sloan Kettering Cancer Center; N: Transfer factor; NA: Not available; ORs: Odds ratios; OS: Overall survival; P: Cisplatin;

PFS: Progression-free survival; PRISMA: Preferred Reporting Items for Systematic Reviews; R: Recombinant human endostatin; RCT: Randomized controlled trial; SFOP: Societe Francaise d'Oncologie Pediatrique; SSG: The Scandinavian Sarcoma Group; SUCRA: Surface Under the Cumulative Ranking; T: Pirarubicin; V: Viscum album; Z: Zoledronate

\section{Acknowledgements}

We thank the authors of the included studies.

Funding

None.

Availability of data and materials

All the data of the manuscript are presented in the paper or additional supporting files.

\section{Authors' contributions}

XjW conceived the study. XjW and $\mathrm{HZ}$ searched the literature and collected the data. XjW, TS, CmT, and KM performed the statistical analysis. XjW and $\mathrm{HZ}$ drafted the manuscript. PW reviewed the manuscript. All authors have read and approved the final paper.

\section{Competing interests}

The authors declare that they have no competing interests.

Consent for publication

Not applicable.

Ethics approval and consent to participate Not applicable.

\section{Publisher's Note}

Springer Nature remains neutral with regard to jurisdictional claims in published maps and institutional affiliations.

\section{Author details}

'Department of Medical Oncology, the First People's Hospital of Yunnan Province, Affiliated Hospital of Kunming University of Science and Technology, Kunming 650032, China. ${ }^{2}$ Department of Thoracic Surgery, the First People's Hospital of Yunnan Province, Affiliated Hospital of Kunming University of Science and Technology, No.157 Jinbi Road, Kunming City 650032, Yunnan Province, China.

Received: 20 January 2017 Accepted: 28 February 2017

Published online: 29 March 2017

\section{References}

1. Dantas-Barbosa C, Brigido MM, Maranhao AQ. Construction of a human Fab phage display library from antibody repertoires of osteosarcoma patients. Genet Mol Res. 2005:4:126-40.

2. Cai S, Zhang T, Zhang D, Qiu G, Liu Y. Volume-sensitive chloride channels are involved in cisplatin treatment of osteosarcoma. Mol Med Rep. 2015;11: 2465-70.

3. Zhang Y, Zhang L, Zhang G, Li S, Duan J, Cheng J, et al. Osteosarcoma metastasis: prospective role of ezrin. Tumour Biol. 2014;35:5055-9.

4. Burns BS, Edin ML, Lester GE, Tuttle HG, Wall ME, Wani MC, et al. Selective drug resistant human osteosarcoma cell lines. Clin Orthop Relat Res. 2001; 383:259-67.

5. Chou AJ, Gorlick R. Chemotherapy resistance in osteosarcoma: current challenges and future directions. Expert Rev Anticancer Ther. 2006;6:1075-85.

6. Wang $Y$, Teng JS. Increased multi-drug resistance and reduced apoptosis in osteosarcoma side population cells are crucial factors for tumor recurrence. Exp Ther Med. 2016:12:81-6.

7. Fan XL, Cai GP, Zhu LL, Ding GM. Efficacy and safety of ifosfamide-based chemotherapy for osteosarcoma: a meta-analysis. Drug Des Devel Ther. 2015;9:5925-32. 
8. Su W, Lai Z, Wu F, Lin Y, Mo Y, Yang Z, et al. Clinical efficacy of preoperative chemotherapy with or without ifosfamide in patients with osteosarcoma of the extremity: meta-analysis of randomized controlled trials. Med Oncol. 2015;32:481.

9. Jian T, Xianbiao X, Yongqian W, Lili W, Bo W, Xian Z, Xuqi S, Mengqi W, Jianqiu K, Gang H, Junqiang Y, Jingnan S. Role of ifosfamide chemotherapy for patients with non-metastatic osteosarcoma: a meta-analysis with 1724 patients. Int J Clin Exp Med. 2016;9:12574-83.

10. Zhuang Y, Wang K. Efficacy and safety of chemotherapy with or without ifosfamide in primary osteosarcoma treatment: a systemic review of randomized controlled trials. Int J Clin Exp Med. 2016;9:10434-42.

11. Wang W, Wang ZC, Shen H, Xie JJ, Lu H. Dose-intensive versus dose-control chemotherapy for high-grade osteosarcoma: a meta-analysis. Eur Rev Med Pharmacol Sci. 2014;18:1383-90.

12. Zhang FY, Tang W, Zhang ZZ, Huang JC, Zhang SX, Zhao XC. Systematic review of high-dose and standard-dose chemotherapies in the treatment of primary well-differentiated osteosarcoma. Tumour Biol. 2014:35:10419-27.

13. Wang WG, Wan C, Liao GJ. The efficacy of high-dose versus moderate-dose chemotherapy in treating osteosarcoma: a systematic review and meta-analysis. Int J Clin Exp Med. 2015;8:15967-74.

14. Yamamoto N, Tsuchiya H. Chemotherapy for osteosarcoma-where does it come from? What is it? Where is it going? Expert Opin Pharmacother. 2013;14:2183-93.

15. Wang G, Zhang Z, Yang M, Xu B, Gao Q, Yang X. Comparative proteomics analysis of human osteosarcoma by 2D DIGE with MALDI-TOF/TOF MS. J Bone Oncol. 2016:5:147-52.

16. Moher D, Liberati A, Tetzlaff J, Altman DG. Preferred reporting items for systematic reviews and meta-analyses: the PRISMA statement. PLoS Med. 2009;6:e1000097.

17. Higgins JP, Altman DG, Gotzsche PC, Juni P, Moher D, Oxman AD, et al. The Cochrane Collaboration's tool for assessing risk of bias in randomised trials. BMJ. 2011:343:d5928.

18. Leucht S, Barnes TR, Kissling W, Engel RR, Correll C, Kane JM. Relapse prevention in schizophrenia with new-generation antipsychotics: a systematic review and exploratory meta-analysis of randomized, controlled trials. Am J Psychiatry. 2003;160:1209-22.

19. White IR, Barrett JK, Jackson D, Higgins JP. Consistency and inconsistency in network meta-analysis: model estimation using multivariate meta-regression. Res Synth Methods. 2012;3:111-25.

20. Li D, Wang $T$, Shen $S$, Cheng $S$, Yu J, Zhang $Y$, et al. Effects of fluroquinolones in newly diagnosed, sputum-positive tuberculosis therapy: a systematic review and network meta-analysis. PLoS One. 2015;10:e0145066.

21. Trinquart L, Chatellier G, Ravaud P. Adjustment for reporting bias in network meta-analysis of antidepressant trials. BMC Med Res Methodol. 2012;12:150.

22. Zhang Y, Ren LF. Clinical analysis of the recombinant human endostatin combined with DIA in the treatment of osteosarcoma. Anti-tumor Pharmacy. 2013;3:368-71.

23. Marina NM, Smeland S, Bielack SS, Bernstein M, Jovic G, Krailo MD, et al. Comparison of MAPIE versus MAP in patients with a poor response to preoperative chemotherapy for newly diagnosed high-grade osteosarcoma (EURAMOS-1): an open-label, international, randomised controlled trial. Lancet Oncol. 2016:17:1396-408.

24. Piperno-Neumann S, Le Deley MC, Redini F, Pacquement H, Marec-Berard P, Petit $\mathrm{P}$, et al. Zoledronate in combination with chemotherapy and surgery to treat osteosarcoma (OS2006): a randomised, multicentre, open-label, phase 3 trial. Lancet Oncol. 2016;17:1070-80.

25. Bielack SS, Smeland S, Whelan JS, Marina N, Jovic G, Hook JM, et al. Methotrexate, doxorubicin, and cisplatin (MAP) plus maintenance pegylated interferon alfa- $2 \mathrm{~b}$ versus MAP alone in patients with resectable high-grade osteosarcoma and good histologic response to preoperative MAP: first results of the EURAMOS-1 good response randomized controlled trial. J Clin Oncol. 2015;33:2279-87.

26. Longhi A, Reif M, Mariani E, Ferrari S. A randomized study on postrelapse disease-free survival with adjuvant mistletoe versus oral etoposide in osteosarcoma patients. Evid Based Complement Alternat Med. 2014;2014: 210198

27. Whelan JS, Jinks RC, McTiernan A, Sydes MR, Hook JM, Trani L, et al. Survival from high-grade localised extremity osteosarcoma: combined results and prognostic factors from three European Osteosarcoma Intergroup randomised controlled trials. Ann Oncol. 2012;23:1607-16.
28. Zhao H, Yao Y, Wang Z, Lin F, Sun Y, Chen P. Therapeutic effect of pirarubicin-based chemotherapy for osteosarcoma patients with lung metastasis. J Chemother. 2010;22:119-24.

29. Chou AJ, Kleinerman ES, Krailo MD, Chen Z, Betcher DL, Healey JH, et al. Addition of muramyl tripeptide to chemotherapy for patients with newly diagnosed metastatic osteosarcoma: a report from the Children's Oncology Group. Cancer. 2009;115:5339-48.

30. Meyers PA, Schwartz CL, Krailo MD, Healey JH, Bernstein ML, Betcher D, et al. Osteosarcoma: the addition of muramyl tripeptide to chemotherapy improves overall survival-a report from the Children's Oncology Group. J Clin Oncol. 2008:26:633-8.

31. Le Deley MC, Guinebretiere JM, Gentet JC, Pacquement H, Pichon F, Marec-Berard P, et al. SFOP OS94: a randomised trial comparing preoperative high-dose methotrexate plus doxorubicin to high-dose methotrexate plus etoposide and ifosfamide in osteosarcoma patients. Eur J Cancer. 2007:43:752-61

32. Meyers PA, Gorlick R, Heller G, Casper E, Lane J, Huvos AG, et al. Intensification of preoperative chemotherapy for osteogenic sarcoma: results of the Memorial Sloan-Kettering (T12) protocol. J Clin Oncol. 1998;16:2452-8.

33. Souhami RL, Craft AW, Van der Eijken JW, Nooij M, Spooner D, Bramwell VH, et al. Randomised trial of two regimens of chemotherapy in operable osteosarcoma: a study of the European Osteosarcoma Intergroup. Lancet. 1997;350:911-7.

34. Link MP. The multi-institutional osteosarcoma study: an update. Cancer Treat Res. 1993;62:261-7.

35. Edmonson JH, Green SJ, Ivins JC, Gilchrist GS, Creagan ET, Pritchard DJ, et al. A controlled pilot study of high-dose methotrexate as postsurgical adjuvant treatment for primary osteosarcoma. J Clin Oncol. 1984;2:152-6.

36. Winkler K, Beron G, Kotz R, Salzer-Kuntschik M, Beck J, Beck W, et al. Neoadjuvant chemotherapy for osteogenic sarcoma: results of a Cooperative German/Austrian study. J Clin Oncol. 1984;2:617-24.

37. Eilber F, Giuliano A, Eckardt J, Patterson K, Moseley S, Goodnight J. Adjuvant chemotherapy for osteosarcoma: a randomized prospective trial. J Clin Oncol. 1987:5:21-6.

38. Sweetnam DR. A trial of chemotherapy in patients with osteosarcoma (a report to the Medical Research Council by their Working Party on Bone Sarcoma. Br J Cancer. 1986;53:513-8.

39. Winkler K, Beron G, Delling G, Heise U, Kabisch $H$, Purfurst $\mathrm{C}$, et al. Neoadjuvant chemotherapy of osteosarcoma: results of a randomized cooperative trial (COSS-82) with salvage chemotherapy based on histological tumor response. J Clin Oncol. 1988;6:329-37.

40. Bramwell VH, Burgers M, Sneath R, Souhami R, van Oosterom AT, Voute PA, et al. A comparison of two short intensive adjuvant chemotherapy regimens in operable osteosarcoma of limbs in children and young adults: the first study of the European Osteosarcoma Intergroup. J Clin Oncol. 1992;10:1579-91.

41. Ivins JC, Ritts RE, Pritchard DJ, Gilchrist GS, Miller GC, Taylor WF. Transfer factor versus combination chemotherapy: a preliminary report of a randomized postsurgical adjuvant treatment study in osteogenic sarcoma. Ann N Y Acad Sci. 1976;277:558-74.

42. Jasmin C. Randomized trial of adjuvant chemotherapy in osteogenic osteosarcoma: comparison of altering sequential administrations of high doses of adriamycin, methotrexate, and cyclophosphamide with a 6-month administration of high-dose adriamycin followed by a low-dose semicontinuous chemotherapy. EORTC Osteosarcoma Working Party Group. Recent Results Cancer Res. 1978;68:28-32.

43. Gilchrist GS, Ivins JC, Ritts Jr RE, Pritchard DJ, Taylor WF, Edmonson JM. Adjuvant therapy for nonmetastatic osteogenic sarcoma: an evaluation of transfer factor versus combination chemotherapy. Cancer Treat Rep. 1978;62:289-94

44. Burgers JM, van Glabbeke M, Busson A, Cohen P, Mazabraud AR, Abbatucci JS, et al. Osteosarcoma of the limbs. Report of the EORTC-SIOP 03 trial 20781 investigating the value of adjuvant treatment with chemotherapy and/or prophylactic lung irradiation. Cancer. 1988;61:1024-31.

45. Goorin AM, Schwartzentruber DJ, Devidas M, Gebhardt MC, Ayala AG, Harris $M B$, et al. Presurgical chemotherapy compared with immediate surgery and adjuvant chemotherapy for nonmetastatic osteosarcoma: Pediatric Oncology Group Study POG-8651. J Clin Oncol. 2003;21:1574-80.

46. Winkler K, Bielack S, Delling G, Salzer-Kuntschik M, Kotz R, Greenshaw C, et al. Effect of intraarterial versus intravenous cisplatin in addition to systemic doxorubicin, high-dose methotrexate, and ifosfamide on histologic tumor response in osteosarcoma (study COSS-86). Cancer. 1990;66:1703-10. 
47. Bacci G, Ferrari S, Tienghi A, Bertoni F, Mercuri M, Longhi A, et al. A comparison of methods of loco-regional chemotherapy combined with systemic chemotherapy as neo-adjuvant treatment of osteosarcoma of the extremity. Eur J Surg Oncol. 2001;27:98-104.

48. Bacci G, Ruggieri P, Picci P, Mercuri M, Ferraro A, Tella G, et al. Intra-arterial versus intravenous cisplatinum (in addition to systemic Adriamycin and high dose methotrexate) in the neoadjuvant treatment of osteosarcoma of the extremities. results of a randomized study. J Chemother. 1996;8:70-81.

49. Bacci G, Picci P, Avella M, Ferrari S, Casadei R, Ruggieri P, et al. Effect of intra-arterial versus intravenous cisplatin in addition to systemic adriamycin and high-dose methotrexate on histologic tumor response of osteosarcoma of the extremities. J Chemother. 1992;4:189-95.

50. Krailo M, Ertel I, Makley J, Fryer CJ, Baum E, Weetman R, et al. A randomized study comparing high-dose methotrexate with moderate-dose methotrexate as components of adjuvant chemotherapy in childhood nonmetastatic osteosarcoma: a report from the Childrens Cancer Study Group. Med Pediatr Oncol. 1987;15:69-77.

51. Makley JT, Krailo M, Ertel IJ, Fryer CJ, Baum ES, Weetman RM, et al. The relationship of various aspects of surgical management to outcome in childhood nonmetastatic osteosarcoma: a report from the Childrens Cancer Study Group. J Pediatr Surg. 1988;23:146-51.

52. Bacci G, Gherlinzoni F, Picci P, Van Horn JR, Jaffe N, Guerra A, et al. Adriamycin-methotrexate high dose versus adriamycin-methotrexate moderate dose as adjuvant chemotherapy for osteosarcoma of the extremities: a randomized study. Eur J Cancer Clin Oncol. 1986;22:1337-45.

\section{Submit your next manuscript to BioMed Central and we will help you at every step:}

- We accept pre-submission inquiries

- Our selector tool helps you to find the most relevant journal

- We provide round the clock customer support

- Convenient online submission

- Thorough peer review

- Inclusion in PubMed and all major indexing services

- Maximum visibility for your research

Submit your manuscript at www.biomedcentral.com/submit

) Biomed Central 